\title{
O desenvolvimento de gênero do discurso argumentativo no ensino superior: uma proposta teórico-metodológica
}

\author{
Marilúcia dos Santos Domingos Striquer \\ Renilson José Menegassi***
}

\section{Resumo}

Este estudo tem como objetivo apresentar uma proposta teórico-metodológica para o trabalho com a produção textual de gênero do discurso argumentativo, no ensino superior. Sustentada pela concepção dialógica de linguagem, originária dos preceitos do Círculo de Bakhtin, e pelos princípios da vertente didática do Interacionismo Sociodiscursivo, a proposta é uma ampliação do que foi realizado na formação de graduandos do curso de Letras para a execução do projeto Pibid. Após análise de textos-diagnósticos produzidos pelos graduandos, uma sequência didática foi elaborada e implementada. A produção final dos acadêmicos demonstrou que a proposta contribuiu para que o texto deixasse de ser apenas um gênero acadêmico constituído como processo e produto da verificação docente do ensino e aprendizado de conteúdos para se tornar materialização de uma prática social instituída em uma situação de interação específica.

Palavras-chave: Gêneros do discurso. Relação dialógica. Produção de texto. Ensino Superior.

\section{Considerações iniciais}

Os diversos documentos orientadores da atividade docente: a Lei de Diretrizes e Bases da Educação - LBD. n. 9394 (BRASIL, 1996); os Parâmetros Curriculares Nacionais (BRASIL, 1998); a Diretriz Curricular Nacional dos cursos de Letras (BRASIL, 2001); a Base Nacional Comum Curricular (BRASIL, 2017), bem como as diversas diretrizes curriculares estaduais estabelecem que

\footnotetext{
Doutora em Estudos da Linguagem. Professora adjunta da Universidade Estadual do Norte do Paraná (Uenp). E-mail:marilucia@uenp.edu.br

** Doutor em Letras pela Universidade Estadual Júlio de Mesquita Filho (UnesP-Assis), com pós-doutorado em Linguística Aplicada pela Universidade Estadual de Campinas (Unicamp). Atua nas linhas de pesquisas Ensino e Aprendizagem de Línguas e Formação do Professor de Línguas. É líder do Grupo de pesquisa Interação e Escrita (UEM/CNPq). Atua na graduação em Letras da Universidade Estadual de Maringá e no Programa de Pós-graduação em Letras da mesma instituição, nos cursos de mestrado, doutorado e na supervisão de pós-doutorado. E-mail: renilson@wnet. com.br
}

Data de submissão: dez. 2018 - Data de aceite: mar. 2019 http://dx.doi.org/10.5335/rdes.v15i1.8914 
o papel da escola, em todos os seus níveis, é o de formar cidadãos que saibam participar das mais diferentes situações comunicativas existentes na sociedade.

Em destaque, o que estabelece a LDB como princípios e fins da educação nacional é que o educando seja preparado para "o exercício da cidadania e sua qualificação para o trabalho" (Art. $2^{\circ}$, BRASIL, 1996). Cabe, então, à escola o desenvolvimento e o aprimoramento contínuo de instrumentos materiais e semióticos, para a formação de cidadãos atuantes em uma sociedade em que as situações comunicativas estão em constante evolução. Situações sociais que Bakhtin (2003) define como campos da atividade humana. Para o autor, o emprego da língua acontece em forma de enunciados, orais ou escritos, os quais, em essência, são concretos, únicos e "refletem as condições específicas e as finalidades de cada referido campo" (BAKHTIN, 2003, p. 261). Ou seja, um indivíduo ao participar de uma interação social, a partir de sua intenção, seu querer e/ou necessidade de dizer, elabora um discurso, o qual está sempre vinculado às especificidades do campo, pois se origina, se integra e reflete os discursos lá instituídos. Esse discurso configura-se em um enunciado, um gênero do discurso que, portanto, está estabilizado social e historicamente dentro do campo e da prática social, e é por meio dos diversos e diferentes gêneros, que se materializam por textos, orais e escritos, que os indivíduos participam da sociedade, interagem entre si.
Muitas pesquisas revelam problemas com o processo de produção de textos no campo acadêmico, não menos diferente nos demais níveis da educação formal. Ao pautarmos nossos estudos no campo acadêmico e no interesse do aprimoramento da formação inicial de professores, trazemos como exemplo a pesquisa de Marinho (2010) ao afirmar que são constantes as queixas de professores universitários e dos próprios alunos de que "os alunos têm dificuldade na leitura e na produção de textos acadêmicos" (p. 364), assim como os estudos de Vitória e Christofoli (2013), para quem as constantes reclamações dos professores são as de que os alunos "pouco escrevem e que existem sérias dificuldades em produzir textos acadêmicos" (p. 42). O destaque maior das duas pesquisas, 0 qual comungamos inteiramente, é para a necessidade da transformação das queixas e dos resultados em propostas de ensino, em elaboração de projetos de intervenção pedagógica, da criação de caminhos para que os textos produzidos pelos acadêmicos/professores em formação inicial ${ }^{1}$ se tornem instrumentos semióticos adequados para a sua participação no ensino superior, nos muitos outros campos existentes na vida cotidiana e no trabalho.

Assim, é preciso atenção para a complexidade que caracteriza os gêneros acadêmicos. Nos diversos campos que há na sociedade, um gênero materializa uma prática social de referência, sendo instrumento semiótico de participação 
dos indivíduos em situações de interação. Exemplos, ao participar do campo cotidiano, diante da necessidade de abastecer a casa com produtos de alimentação e higiene, um indivíduo produz o gênero lista de compra, o qual se concretiza em um texto com características composicionais-estilísticas específicas; a mesma pessoa, ao estar inserida no campo acadêmico, a fim de divulgar uma pesquisa realizada, produz o gênero artigo científico, o qual tem outras e suas características próprias e se materializa por um texto que pode ser publicado em um periódico científico, em anais de evento etc.

No campo acadêmico, sobretudo, no processo de formação inicial docente, a natureza de muitos dos gêneros é mais ampla, uma vez que se configuram a priori como processo e produto da aprendizagem de conteúdos, devendo ser também materialização de uma prática que existe em outro campo da atividade, e ainda um conteúdo a ser tomado como objeto de ensino quando do momento do exercício da profissão pelo acadêmico. Em exemplificação, na formação inicial de professores após o ensino dos elementos que constituem um gênero, por exemplo, do gênero redação do Exame Nacional do Ensino Médio (Enem) e de suas operações de uso, o professor solicita a produção de um exemplar desse gênero, a fim de verificar, avaliar e acompanhar o processo de ensino e aprendizagem, bem como sua apropriação e desenvolvimento. Em decorrência, o texto produzido pelo aluno é o produto de comprovação do que apreendeu do conteúdo em abordagem; mas esse texto deve configurar-se, principalmente, como a materialização da prática social de referência, que existe fora do campo acadêmico, e ainda, deve ser apreendido para que, no momento de sua atuação como professor, o gênero seja conteúdo a ser por ele ensinado a seus alunos, numa nítida relação de interação.

Diante dessas questões, este estudo tem como objetivo apresentar uma proposta teórico-metodológica para o trabalho com a produção textual de gênero do discurso argumentativo, no ensino superior. Centramo-nos em explicitar os procedimentos adotados para a construção da proposta, a qual pode contribuir para que os graduandos ultrapassem a etapa em que o gênero é apenas processo e produto da aprendizagem de conteúdos, para se tornar instrumento que orienta uma prática de referência.

A proposta está articulada à concepção dialógica de linguagem, originária dos preceitos do Círculo de Bakhtin (BAKHTIN, 2003; 2016; BAKHTIN/ VOLOCHINOV, 2006), entrelaçada aos princípios da vertente didática do Interacionismo Sociodiscursivo (DOLZ; NOVERRAZ; SCHNEUWLY, 2004). É uma ampliação do que foi realizado na execução de um projeto de ensino vinculado ao Programa Institucional de Bolsa de Iniciação à Docência (Pibid) da Universidade Estadual do Norte do Paraná (Uenp), do campus Jacarezinho, em que 
o objetivo foi promover que os bolsistas Pibid/professores em formação inicial nos Cursos de Letras se apropriassem do gênero Redação do Enem, a fim de que pudessem atuar como mediadores no ensino desse gênero para alunos da educação básica atendidos pelo projeto. Para tanto, os coordenadores do projeto/professores do curso de Letras elaboraram uma série de ações. Assim, apresentamos, na sequência: a) a análise das 22 redações produzidas pelos graduandos-bolsistas, após a realização de estudos dirigidos. Textos configurados como diagnóstico para o planejamento das ações da coordenação e para a elaboração da proposta de intervenção; b) a proposta teórico-metodológica elaborada a partir do diagnosticado (que para este trabalho sofreu ampliações do efetivamente realizado); c) considerações sobre a produção final dos graduandos após a intervenção.

Este trabalho está vinculado ao projeto de pesquisa "Gêneros discursivos/textuais: dos documentos prescritivos à sala de aula", desenvolvido na Universidade Estadual do Norte do Paraná (UENP), e ao projeto "Escrita, revisão e reescrita na formação docente", desenvolvido na Universidade Estadual de Maringá, com financiamento da Fundação Araucária do Paraná.

\section{A natureza dos enunciados}

Pautados sobre o trabalho com gêneros acadêmicos e diante da complexidade que os fundamenta, recorremos aos estudos do Círculo de Bakhtin sobre a natureza dos enunciados. De acordo com Bakhtin (2003), o emprego da língua acontece em forma de enunciados, orais ou escritos, os quais são sempre concretos e únicos, porque, ao materializar o discurso de um indivíduo, o enunciado está permeado pelo querer ou pela necessidade de dizer desse indivíduo que é singular, bem como pela singularidade da interação que é sempre irrepetível. Diante do caráter dialógico que funda a linguagem, a subjetividade se constrói no coletivo social, estando vinculada às normas sociais (BAKHTIN/VOLOCHINOV, 2006). Em decorrência, os enunciados refletem as características e as finalidades dos campos da atividade humana nos quais estão inseridos (BAKHTIN, 2003), porque todo enunciado dialoga, ou seja, tem relação de sentido com outros discursos anteriores, responde-lhes e suscita que outros posteriormente aconteçam. Nas palavras de Bakhtin (2003, p. 288), "Em todos os seus caminhos até o objeto, em todas as direções, o discurso se encontra com o discurso de outrem e não pode deixar de participar, com ele, de uma interação viva e tensa".

É na interação social que os discursos se encontram, na aceitação, na rejeição, na transformação, na ampliação dos já- 
-ditos, sentidos possíveis para a enunciação vão sendo concebidos e estabilizados pela coletividade na qual o discurso está inserido. De acordo com Menegassi e Cavalcanti (2013, p. 434), a enunciação "tem como centro organizador o meio social e não poderá ser compreendida e explicada fora desse vínculo com a situação concreta de sua manifestação". Esses diálogos travados dentro do contexto socio-histórico de produção da enunciação, os quais fazem parte da construção de sentidos, nem sempre estão marcados linguisticamente no enunciado. Já no enunciado, que é o objeto material, observável, "o dialogismo é uma forma composicional" (FIORIN, 2008, p. 32), isto é, os enunciados são formados por elementos que manifestam a relação dialógica entre os participantes da interação, por meio dos três elementos que, segundo Bakhtin (2003, p. 268), são "indissoluvelmente ligados ao todo do enunciado": o conteúdo temático, a construção composicional e o estilo.

O conteúdo temático, para o Círculo de Bakhtin, é o assunto tratado no texto mais a apreciação de valor que o produtor lhe confere, considerando, destacamos, a situação comunicativa de onde participa o texto. É por esse motivo que Rojo e Barbosa (2015, p. 88) entendem que "O tema é o sentido de um dado texto tomado como um todo, 'único e irrepetível', justamente porque se encontra viabilizado pela refração da apreciação de valor do locutor no momento de sua produção". Esse locutor é um ser imbuí- do de valores construídos nas relações sociais com os discursos precedentes ao seu e com aqueles por ele previstos/ esperados como posteriores. Explicam Menegassi e Cavalcanti (2013, p. 434),

[...] mesmo que o enunciado verbal seja repetido, ele não será valorativamente o mesmo, pois o contexto de produção [de cada enunciação] é sócio-histórico-contextual-discursivamente diverso, considerando-se aqui tanto a sua produção inicial, quanto seus modos de recepção, nas diversas possibilidades complexas da concretização da linguagem (inserção nossa).

O estilo do gênero são as escolhas linguísticas para que o autor diga o que quer dizer, são as palavras, as formas linguísticas-gramaticais empregadas em um texto, e, de acordo com Bakhtin (2016, p. 129), "a palavra é determinada não só por sua relação com o objetivo, mas também por sua relação com a palavra do outro (o estilo do outro)". O mesmo acontece com a organização estrutural, com as escolhas de como o conteúdo temático pode progredir textualmente, o formato estrutural, o tipo de discurso e o tipo de texto são selecionados por todos os aspectos que formam a enunciação.

Em convergência com essas definições, a orientação de Bakhtin/Volochinov (2006) para um estudo sociológico da linguagem, a qual podemos pensar também para o ensino, é a de que esteja em foco:

1. As formas e os tipos de interação verbal em ligação com as condições concretas em que se realiza;

2. As categorias de atos de fala na vida e na criação ideológica em relação a suas determinações pela interação verbal; 
3. A mudanças e evoluções das formas da língua levando-se em consideração que as relações sociais evoluem, a comunicação evolui, a interação social evoluí, por consequência, a forma da língua evolui (BAKHTIN/VOLOCHINOV, 2006, p. 128).

Tal encaminhamento evidencia que a linguagem deve ser observada a partir do campo da atividade humana da qual participa, das práticas sociais de linguagem que lá se estabelecem, do entendimento de qual é a intenção sociocomunicativa do produtor do texto, a quem ele se dirige, no que e como os discursos instituídos no momento e no lugar de produção e recepção influenciam na interação, aspectos que se refletem nos gêneros do discurso por meio dos elementos que o formam: o conteúdo temático, a construção composicional e o estilo.

Ao tomar os preceitos do Círculo de Bakhtin como ponto de partida, os estudiosos da vertente didática do Interacionismo Sociodiscursivo (ISD) sugerem uma metodologia para que um gênero que existe em situação de interação real, em ambientes naturais, se transforme em objeto de ensino e de aprendizagem escolar. Essa metodologia, denominada de sequência didática de gêneros, é a que adotamos para a construção de nossa proposta.

A seguir, ao apresentarmos o projeto Pibid e as ações desenvolvidas pela coordenação para a formação dos graduandos que atuariam nas salas de aula da educação básica, expomos os procedimentos realizados para a construção da proposta teórico-metodológica que é o foco deste artigo.

\section{O projeto Pibid e o processo formativo}

A equipe Pibid foi formada por 2 professores do ensino superior, coordenadores do projeto; 4 professoras da rede básica de ensino, supervisoras das atividades; 22 graduandos dos cursos de Letras/Espanhol e Letras/Inglês da Uenp, campus Jacarezinho-PR. O projeto teve vigência nos anos de 2014 a 2017. Os coordenadores/professores do curso de Letras elaboraram uma série de ações com vistas ao aprimoramento da produção textual do gênero Redação do Exame Nacional do Ensino Médio (Enem), pelos graduandos-bolsistas. O projeto atendeu, em uma de suas linhas de atuação, alunos do último ano do ensino médio, com o objetivo de auxiliá-los no desenvolvimento de capacidades de linguagem para a produção da redação do Enem. Assim, para que fosse possível que os graduandos pudessem auxiliar os alunos, primeiro tiveram que se apropriar do gênero e de suas operações de uso (SCHNEUWLY, 2004).

O processo formativo aconteceu da seguinte forma: foram realizados estudos dirigidos e discussões dos preceitos do Círculo de Bakhtin a respeito de interação verbal, dialogismo, dos gêneros discursivos; da proposta da metodologia de sequências didáticas do ISD; sobre as matrizes de referência e os documentos prescritivos que constituem o exame e a redação do Enem; e sobre as características que formam $o$ 
gênero textual intitulado pelo Enem de texto dissertativo-argumentativo. Em um segundo momento, os graduandos participaram de um simulado organizado pela coordenação, conscientes de que o texto produzido naquele momento serviria de diagnóstico. De acordo com a metodologia da sequência didática de gêneros de Dolz, Noverraz e Schneuwly (2004), esse procedimento é denominado de "primeira produção", ferramenta que permite identificar as capacidades que os alunos já têm, quais suas potencialidades, e quais os pontos que necessitam de desenvolvimento. Sob esse prisma, a primeira produção manifesta a prática de verificação docente do ensino e do aprendizado dos conteúdos estudados pelos graduandos, ao mesmo tempo que deve ser, em simulação, instrumentos de sustentação e de orientação de participação dos alunos no Enem.

Os comandos de produção para a escrita do texto se estruturaram exatamente como no Enem, assim como o comportamento exigido do participante: tempo determinado para a produção textual; organização do texto conforme critérios do Exame; apresentação de textos de apoio, instruções, na folha de redação sobre a organização do texto e oferecimento de um tema, no caso: "Imagens, discursos e representações sociais presentes na mídia televisiva e na web podem ser incorporadas por adolescentes ao ponto de influenciar comportamentos e a formação para a vida adulta”. Os textos produzidos estão expostos, por amostragem, na próxima seção.

\section{Os textos produzidos}

A partir do encaminhamento sociológico proposto por Bakhtin/Volochinov (2006) e considerando os preceitos sobre a natureza dos enunciados defendidos pelo Círculo de Bakhtin, analisamos os 22 textos dissertativos-argumentativos produzidos pelos graduandos. Nosso primeiro olhar sobre o corpus norteia-se pela assertiva de Bakhtin/Volochinov (2006, p. 116) de que "Qualquer que seja o aspecto da expressão-enunciação considerado, ele será determinado pelas condições reais da enunciação em questão, isto é, pela situação social mais imediata" (grifo dos autores). O Enem é um exame que tem como objetivo ser uma ferramenta de avaliação da qualidade do ensino médio e, a partir de sua reformulação em 2009, ser um "mecanismo único, alternativo ou complementar para acesso à educação superior, especialmente a ofertada pelas Instituições Federais de Educação Superior" e "acesso a programas governamentais de financiamento ou o apoio ao estudante da educação superior" (conf. Edital 13/2017)2. Nesse sentido, o exame é uma política pública voltada a promover melhorias no sistema educacional brasileiro e igualdade de direito de acesso às universidades públicas ou aos programas sociais subsidiados pelo poder público às camadas estratificadas como economicamente mais carentes e aos estudantes oriundos de escolas da rede pública de ensino apontadas por diversos indicadores, entre eles 
o Programa Internacional de Avaliação de Estudantes (Pisa), como de menor desempenho em relação as particulares.

Considerando esse contexto socio-histórico (BAKHTIN, 2003), para que todos tenham a mesma condição de participação no ENEM, as regras e normas são elaboradas, tendo como destinatários esse grande coletivo, os interessados em ingressar no ensino superior ou em programas sociais relacionados a esse nível de ensino. Essas regras e normas formam a Matriz de Referência do Enem e a Cartilha do participante ${ }^{3}$. Documentos que inserem cada um dos indivíduos participantes no sistema de normas sociais coletivas (BAKHTIN/VOLOCHINOV, 2006), o que relaciona-se ao que Volochinov (2013) apresenta como os fatores que compõem o contexto extraverbal da enunciação: "1) um horizonte espacial comum por ambos os falantes [...]"; 2) $o$ conhecimento e a compreensão comum da situação, igualmente compartilhados pelos dois, e, finalmente, 3) a avaliação compartilhada pelos dois, desta situação" (VOLOCHINOV, 2013, p. 78, grifos dos autores). Nesse caso, o falante e seu interlocutor são todos os envolvidos: os responsáveis pela execução administrativa e pedagógica do exame em todas as suas instâncias: o Ministério da Educação, o Instituto Nacional de Estudos e Pesquisas Educacionais Anísio Teixeira (Inep), autarquia vinculada ao Ministério da Educação, incumbido direto pelo Enem; os indivíduos que realizam as provas, concebidos na situação como aqueles que assumem o papel social de candidatos às vagas no ensino superior e nos programas; os avaliadores das provas, uma banca de professores formados em Letras; os professores da educação básica e de cursinhos, os quais preparam os candidatos para participação na situação de avaliação em questão.

A partir desses princípios, os resultados de nossas análises demonstram que os acadêmicos não tinham se apropriado, até aquele momento da primeira produção, do gênero em processo e de suas operações de uso. Conforme relatamos na seção anterior, na primeira fase da organização do projeto, a equipe realizou estudos sobre as matrizes de referência, a Cartilha do participante e as características que formam o texto dissertativo-argumentativo. Mas os graduandos não respondem aos discursos explicitados nesses documentos, não constroem seus textos considerando a função de interação específica que é o Enem e o contexto socio-histórico que o constitui; não assumem o papel social de candidatos a eles determinados; não direcionam seus textos aos corretores da redação. De forma sintética, dos 22 textos, 10 deles (quase $50 \%$ do total) não organizam o texto a partir da estrutura dissertativo-argumentativa exigida pelo Exame. A seguir, transcrevemos dois exemplares ${ }^{4}$ exatamente como foram escritos pelos alunos, como comprovação de nossas assertivas. 


\section{Texto 1:}

\section{A influência das mídias nos adolescentes}

Nos dias de hoje, a mídia televisiva e a internet contribuem para trazer informação, porém influenciam crianças, jovens e adultos de formas positivas e negativas nas pessoas.

A mídia especificamente, tem o poder de mudar a opinião das pessoas e em relação aos jovens, não é diferente. Os adolescentes são mais sucetíveis a serem influenciados e por isso pode ser prejudicados ou não.

Quando se fala a respeito de política, por exemplo, a mídia e as redes sociais são capazes de persuadirem uma grande parte da população a mudar de partido, e isso influencia a formação da vida adulta desses jovens e seus comportamentos.

Com isso, a influência das mídias são boas no sentido de os jovens refletirem mais a respeito do assunto tratado, porém pode ser prejudicial por influenciar em suas vidas, de maneira negativa no adolescente.

O determinado na Cartilha do participante (BRASIL, 2017) é que o candidato deve elaborar um texto com a apresentação de uma tese, argumentos e uma proposta de intervenção para o problema em abordagem. Para tanto, o graduando recebe um tema, em nossa proposta pedagógica, o tema versa sobre o fato de imagens, discursos e representações sociais veiculados pela mídia televisiva e pela internet poderem ser incorporados pelos adolescentes, influenciando seus comportamentos e sua formação. $\mathrm{O}$ discurso instituído no Texto 1 tem relação (BAKHTIN, 2003) com os discursos do comando de produção e da Cartilha do participante, é possível observar que autor aponta que a influência pode ser tanto positiva como negativa, porém não elaborada uma tese para a questão. No segundo parágrafo, inicia a exposição de um argumento quando da menção de que os adolescentes são mais suscetíveis às influências, mas não há progressão. Também na apresentação de que a televisão e a mídia "são capazes de persuadirem uma grande parte da população a mudar de partido", nenhuma explicação é apresentada sobre como isso ocorre e nem como é agravante para a formação dos adolescentes. Logo, o texto vai de encontro do que determina a Cartilha sobre o que é um texto dissertativo-argumentativo: "É mais do que uma simples exposição de ideias e, por isso, você deve evitar elaborar um texto de caráter apenas expositivo, assumindo claramente um ponto de vista" (BRASIL, 2017, p. 15). Consequentemente, os aspectos que formam o contexto socio-histórico da situação social imediata não são considerados pelo autor do Texto 1. Os graduandos tinham ciência de que deveriam produzir uma redação no formato exigido pelo Enem, que a situação comunicativa era a de simulado do exame, e que o objetivo maior da atividade era que a coordenação pudesse diagnosticar o quanto dominavam o gênero em questão e as operações de linguagem que o constitui. 
Sobre a maneira que o enunciado se apresenta, é possível ainda apontar que o texto demonstra que o aluno não tem domínio das competências exigidas pelo exame. Por exemplo, o Texto 1 não é organizado a partir da modalidade escrita formal da língua portuguesa, tem problemas: a) com concordância nominal: "Os adolescentes são mais sucetíveis a serem influenciados e por isso pode ser prejudicados ou não"; b) com a ortografia: "sucetíveis"; c) com pontuação: "A mídia especificamente, tem o poder..."; d) não aplica conceitos de áreas de conhecimento; e) não defende um ponto de vista e em decorrência não demonstra conhecimentos de mecanismos para a construção da argumentação: o ponto de vista é o de que a mídia influência de forma positiva e negativa os adolescentes, mas, no segundo parágrafo existe apenas a repetição da afirmação: "pode ser prejudicados ou não"; o que ocorre também no terceiro parágrafo: "isso influencia a formação da vida adulta desses jovens e seus comportamentos"; no quarto parágrafo um argumento começa a ser desenvolvido na exposição de que "Com isso, a influência das mídias são boas no sentido de os jovens refletirem mais a respeito do assunto tratado", contudo, não há progressão, o leitor não tem condições de saber que assunto tratado seria esse; f) e ainda há uma contradição na colocação de que: "porém pode ser prejudicial por influenciar em suas vidas, de maneira negativa no adolescente".
Importante destacar que mesmo tomando os elementos que constituem a estrutura dissertativo-argumentativa como objeto de estudo na primeira etapa de trabalho da equipe, entre os 10 textos que não organizam o enunciado dentro da estrutura dissertativo-argumentativa, um deles é predominante narrativo. $\mathrm{O}$ autor conta o enredo de uma série americana na qual a personagem principal, uma adolescente, comete suicídio. $\mathrm{O}$ autor, portanto, não assume um papel discursivo adequado para participar do campo e da prática social de linguagem de apresentação de um ponto de vista, argumentos e proposta de intervenção.

Os textos não estão adequados às condições da enunciação ainda por questões que envolvem fatores como: 8 (36\%) dos 22 textos não obedecem a extensão de no máximo 30 linhas. A cartilha do participante do Enem expõe que é atribuída nota zero à redação de extensão de até sete linhas, nada abordando sobre o máximo, porém, a própria folha definitiva de prova já tem o número máximo de 30 linhas. Uma das redações, entre as $8 \mathrm{em}$ abordagem, chegou ao número de 55 linhas. O graduando virou a folha de prova e continuou o texto no verso. Atitude que vai totalmente contrária aos preceitos da situação imediata, das condições concretas em que se realiza a interação verbal (BAKHTIN/VOLOCHINOV, 2006). Seguir o número de linhas estabelecido não é uma questão de estruturação do fato puramente linguístico, mas de adequação desses fatores ao contexto da 
interação e organização de um conteúdo temático, de uma relação dialógica com os critérios exigidos pelo Exame (BAKHTIN, 2016). Essas 8 redações não alcançariam uma boa pontuação, que é o objetivo da sua produção na situação do Enem e, portanto, também não é o que realizam no simulado construído pela coordenação do Pibid.

Sobre as outras 11 redações, do conjunto de 22 totais, elas estão organizadas de acordo com a estrutura imposta pela situação comunicativa, contudo também não refletem de forma adequada o campo e a prática onde estão inseridas. Com o intuito de exemplificar nossa afirmação, transcrevemos um representante médio do segundo conjunto de 11 redações.

\section{Texto 2:}

Desde que a televisão foi inventada, ela têm sido grande destaque nas casas dos brasileiros, é a hora do lazer e descanso depois de trabalhar o dia todo, assim como a tv, a internet tomou conta da vida das pessoas de variada faixa etária, e pode ser utilizada em muitos aparelhos, o que a torna mais acessível. Essas duas grandes redes de comunicação contém diversos conteúdos transmitidos diariamente como talkshows, jornais, telenovelas e também sites de notícia e fofoca, canais de youtube, entre outros. A questão é que ambas têm imenso alcance e por isso, algum impacto, que pode tornar-se um perigo para a sociedade, a exemplo dos adolescentes, que estão moldando a si, descobrindo-se e ao mundo, quanto poder tem a mídia televisiva e na web de influência na opinião e escolhas desses jovens.

Recentemente foi descoberto um jogo polêmico fora e dentro do país, o jogo da "Baleia azul" que continha cinquenta etapas de tortura, sendo a última o suicídio, os participantes comunicavam-se por meio de redes sociais e aplicativos e eram ameaçados caso quisessem desistir. Vale ressaltar que todos os adolescentes que decidiram participar do jogo sofriam de depressão, alguns até desconhecida pelos pais.

A adolescência é um período complexo de transição, a maioria sente-se perdida e insatisfeita com tudo a sua volta, e muitas vezes consigo próprio. Esta é a fase em que os pais mais devem atentar para à situação dos seus filhos, pois estão frágeis, o que os tornam manipuláveis. É possível perceber então, que não é o jogo que levou tantos jovens ao extremo de tirar a própria vida, não sozinho, mas o maior culpado foi o transtorno psicológico que estavam sofrendo. Tem jovem que recebe uma boa educação, tem exemplo de caráter dentro de casa, uma relação amigável com os pais e também, claro, boas companhias, dificilmente se perderá nessa doença tão forte, que pode vir por qualquer motivo em que a pessoa não consiga combater a própria tristeza, por isso é tão importante a participação e percepção dos pais quanto ao comportamento dos filhos.

Portanto, um jovem não receberá influência exterior se estiver bem resolvido e preparado interiormente, este é 
um trabalho em conjunto que deve ser feito por pessoas queridas e próximas desse adolescente, caso contrário a mídia exposta nos aparelhos de tv, tablete ou outro, terá impacto negativo, e as vezes irreversível nestas jovens vidas.

Destacamos o emprego de uma expressão modalizadora no Texto 2 que se relaciona com os sentidos da temática proposta: o enunciado do tema é o de que o veiculado pela TV e pela web podem ser incorporados ao ponto de influenciar os adolescentes, no texto do graduando a ideia é a de que a TV e web tem "algum impacto, que pode tornar-se um perigo para a sociedade", o que leva o leitor à compreensão de que o ponto de vista é que existe a possibilidade da influência. Contudo, na sequência, a afirmativa é contraditória a essa ideia: "quanto poder tem a mídia televisiva e na web de influência na opinião e escolhas desses jovens".

No parágrafo, nem a primeira nem a segunda ideia são desenvolvidas. $\mathrm{O}$ autor narra que um jogo da web influenciou participantes de forma negativa, mas que a culpa não é dessa mídia, e sim dos responsáveis que não acompanham o que os adolescentes fazem e não dão atenção aos problemas psicológicos enfrentados pelos jovens nessa faixa etária. Nesse sentido, um novo ponto de vista é apresentado, que a influência exercida sobre a mídia é consequência da má conduta dos responsáveis. A proposta de intervenção limita-se a apontar que, se essa situação não for revertida, os impactos da mídia sobre os adolescentes serão irreversíveis. Nesse sentido, mesmo que bastante fragilizado, o Texto 2 tem uma estrutura de apresentação de um ponto de vista, que vai se modificando, mas para um deles há a construção de uma explicativa, novamente, mesmo que bastante simplista e fragilizada pela articulação com proposições do senso comum. A proposta de intervenção tem alta previsibilidade informativa.

Sobre a organização textual, baseados em Bakhtin (2016), na constituição interna dos enunciados,

O que determina a seleção dos recursos linguísticos e estilísticos: 1) o conteúdo semântico-objetal (isto é, o direcionamento para o objeto do discurso); 2) a expressividade, ou seja, a expressão do sujeito falante (suas emoções, suas relações com o objeto do discurso); 3) a relação com o ouvinte e com o discurso do outro (de uma terceira pessoa) (BAKHTIN, 2016, p. 135).

Não é o que observamos no Texto 2 , o interlocutor direto não foi considerado. Os graduandos, ressaltamos, tinham ciência de que deveriam produzir uma redação no formato exigido pelo Enem, que a situação comunicativa era a de simulado do exame, Nesse sentido, a natureza dos enunciados produzidos pelos alunos não se caracterizam pela definição de Bakhtin/Volochinov (2006) de que "A palavra dirige-se a um interlocutor: ela é função da pessoa desse interlocutor: variará se se tratar de uma pessoa do mesmo grupo social ou não, se esta for inferior ou superior na hierarquia social, se estiver ligada ao locutor por laços sociais mais ou menos estreitos 
(pai, mãe, marido, etc.)" (p. 116, grifos dos autores). Os coordenadores do Pibid são professores do ensino superior com formação na mesma área do projeto, em Letras, isto é, a seleção e a organização do texto não consideram os aspectos que formam o contexto extraverbal da enunciação (VOLOCHINOV, 2013).

De acordo com o que o exame determina como sendo as competências a serem avaliadas, o autor do Texto 2 demonstra problemas em quase todas as cinco competências: no domínio da modalidade escrita formal da língua: a) na organização de parágrafos; b) com a pontuação; c) com a regência: d) com a organização de elementos coesivos. Problemas não são de ordem da língua, porque conforme Bakhtin (2016, p. 146), "As palavras são os tijolos, a gramática são as regras e os meios da construção, do edifício - isto é o enunciado".

A partir do diagnóstico, passamos a refletir sobre os problemas apresentados nos textos. A primeira produção evidenciou que a maioria dos graduandos, mesmo depois de participarem de estudos dirigidos, não tinham se apropriado do gênero e de suas operações de uso, demonstrando não terem condições de atuarem como mediadores no ensino do gênero em salas de aula da educação básica atendidas pelo projeto Pibid. Uma das conclusões a que chegamos foi a de que a série de estudos realizados não foi suficiente e/ou não foi executada de forma adequada a promover a aprendizagem e desenvolvimento de capaci- dades de linguagem para a produção do gênero redação do Enem pelo grupo de acadêmicos. No decurso, elaboramos uma proposta teórico-metodológica direcionada ao trabalho com os pontos levantados como problemáticos, a qual apresentamos a seguir.

\section{A proposta teórico-metodológica}

A partir da orientação de Bakhtin/Volochinov (2006) sobre o encaminhamento a ser dado para o estudo da linguagem, os integrantes da vertente didática do ISD, Dolz, Noverraz e Schneuwly (2004) sugerem que as primeiras atividades de uma sequência didática contemplem ações para levar o aprendiz a compreender em qual situação comunicativa ele pode agir com o gênero em abordagem. $\mathrm{O}$ aluno deve receber informações a respeito da função/finalidade social comunicativa do gênero, de onde veio aquele gênero (historicidade), os temas que podem ser por ele abordados; a quem se dirige; que formato assume o enunciado em decorrência da situação comunicativa da qual participa. Norteados por esses princípios, os aspectos diagnosticados como problemáticos nos textos produzidos pelos graduandos foram abordados por meio de diferentes atividades. A seguir, apresentamos algumas delas, com adaptações/ampliações realizadas a partir de todo o processo de reflexão e avaliação das ações executadas e dos resultados alcançados pela coordenação 
do projeto, pensando na situação de que são professores em formação.

Oficina 1: As características gerais do campo da atividade humana onde o gênero está inserido e os elementos que formam o contexto de produção.

Atividades: Os acadêmicos são divididos em dois grupos, cada grupo realiza uma das pesquisas e elabora murais com as informações obtidas:

a) Pesquise sobre o que é o Enem, porque foi criado, quais são os objetivos atuais do exame, quem pode participar, quais são as maneiras de participação;

b) Pesquise o que fazer com a nota alcançada no Enem; qual é a média alcançada pelos participantes no exame de forma geral e na redação; o que é e como funciona o Sistema de Seleção Unificada (Sisu), o Sistema de Seleção da Educação Profissional e Tecnológica (Sisutec) o Programa Universidade para Todos (Prouni) e o Financiamento Estudantil (Fies).

Debata com a sala as informações dos murais:

1. Como ingressar em uma instituição pública de ensino utilizando a nota do Enem?

2. Como participar de programas de bolsas e financiamento estudantil em instituição da rede privada do ensino superior utilizando a nota do Enem?

3. A Cartilha do participante do Enem (BRASIL, 2017) explica que não há uma lista de conteúdos a serem estudados para o exame, tanto nas provas objetivas como na redação: "Os aspectos a serem avaliados relacionam-se às competências que devem ter sido desenvolvidas durante os anos de escolaridade" (p. 7). As competências estão descritas na Matriz de Referência do Enem ${ }^{5}$, por isso leia a Matriz de referência de Linguagens, Códigos e suas Tecnologias e discuta com os demais colegas o que o exame espera que o participante aplique, conheça, compreenda, demonstre, analise, interprete, identifique, etc., nas provas objetivas.

4. Leia as cinco competências apresentadas na Cartilha do participante, que serão avaliadas pelos corretores da prova de Redação, e discuta com os colegas o que o exame espera da redação produzida pelo participante.

5. Aquele que participa do Enem deve assumir um posicionamento de candidato a uma vaga no ensino superior. Como esse papel se reflete na produção da redação?

É preciso encaminhar a atenção do aluno para a compreensão do que é o Enem como um campo da atividade humana específico, quais suas características, seus objetivos, quais são as condições impostas por essa situação social imediata que deve refletir no aspecto da expressão-enunciação a ser elaborada pelos participantes (BAKHTIN/VOLOCHINOV, 2006). O Enem sendo uma política pública voltada à igualdade de acesso ao ensino superior, 
para que todos os participantes tenham a mesma condição, regras e normas são estabilizadas, é preciso que os participantes as conheçam. Além das provas objetivas, o participante deve produzir uma redação, e para a abordagem ao tema e organização da estrutura formal e do estilo do gênero a Cartilha descreve quais são as normatizações específicas. Portanto, pelos documentos regulamentadores e prescritivos, é dado a conhecer o horizonte espacial, os conhecimentos e compreensão exigida e avaliação da situação que deve ser comum a todos (BAKHTIN/VOLOCHINOV, 2006).

\section{Responda também:}

6. Quem corrige a redação do ENEM?

7. São para os corretores única e exclusivamente que o autor da redação deve dirigir o seu texto? Justifique sua resposta.

8. Quais das cinco competências que o autor da redação deve demonstrar ter que se relaciona de forma direta a quem é o corretor do texto:

( ) Competência 1: Demonstrar domínio da modalidade escrita formal da língua portuguesa.

( ) Competência 2: Compreender a proposta de redação e aplicar conceitos das várias áreas de conhecimento para desenvolver o tema, dentro dos limites estruturais do texto dissertativo-argumentativo em prosa.

( ) Competência 3: Selecionar, relacionar, organizar e interpretar informações, fatos, opiniões e argumentos em defesa de um ponto de vista.

( ) Competência 4: Demonstrar conhecimento dos mecanismos linguísticos necessários para a construção da argumentação.

( ) Competência 5: Elaborar proposta de intervenção para o problema abordado, respeitando os direitos humanos (BRASIL, 2017, p. 8).

9. Como é atribuída nota à redação?

Se todo enunciado dialoga com discursos anteriores e suscita discursos posteriores, conforme explica Bakhtin (2003), é preciso promover o encontro do aluno com os discursos das prescrições e com o destinatário de seu texto, é com eles que a redação deve ter relação de sentido, deve participar de uma interação viva (BAKHTIN, 2003). De acordo com Menegassi e Cavalcanti (2003), os diálogos travados no contexto da produção da enunciação fazem parte dos sentidos dados aos enunciados, não há, como o aluno produzir uma redação para o Enem sem que esteja vinculada ao que é determinado como particular dessa situação concreta de interação.

Sob essa perspectiva, as primeiras produções foram analisadas e as atividades que formam essa proposta pedagógica foram construídas, pelo princípio de que o enunciado, como material observável, concreto, está marcado pelo diálogo entre os participantes da intera- 
ção. É preciso que a atenção do docente em formação inicial seja dirigida para essa questão, para que ele saiba, por sua vez, no exercício da docência, tomar como objeto de ensino e aprendizagem o gênero, que é materialização de uma prática social de linguagem, e não apenas os aspectos estruturais e estilísticos que formam um texto.

Oficina 2: A prática social de linguagem materializada pelo gênero e $o$ conteúdo temático que o constitui.

A redação do Enem é um texto classificado como dissertativo-argumentativo. Explica a Cartilha (2017) que é argumentativo porque defende uma opinião apresentada pelo autor e é dissertativo porque utiliza de explicações para justificá-la, visando convencer o leitor da relevância da opinião. Logo, por existirem vários gêneros formados pela tipologia textual do argumentar, isto é, pelo qual o autor expõe sua opinião sobre determinado assunto e visa defendê-la, é preciso dirigir a atenção do acadêmico para as singularidades do gênero redação do Enem. A apreciação de valor dada pelo produtor do texto ao tema sofre modificações conforme a situação comunicativa da qual participa o enunciado, para Bakhtin/Volochinov (1992, p. 129), "o tema deve apoiar-se sobre uma certa estabilidade da significação; caso contrário, ele perderia seu elo com o que precede e o que segue, ou seja, ele perderia, em suma, o seu sentido". Nesse sentido, explicam os autores, "o tema da enunciação é determinado não só pelas formas linguísticas que entram na composição, mas igualmente pelos elementos não verbais da situação" (BAKHTIN/ VOLOCHINOV, 2006, p. 128). Com efeito, expor e defender uma opinião em uma carta do leitor é diferente de fazê-lo em um editorial, em uma conversa informal cotidiana com familiares, em uma redação. A carta do leitor e o editorial, por exemplo, viabilizam discursos e posições instituídas no campo jornalístico; a conversa informal os discursos que circulam no campo cotidiano/familiar; e a redação do Enem, os do campo escolar.

Atividades: Em nosso dia a dia, nas diversas situações que participamos, uma das práticas muito frequentes é dar nossa opinião a respeito dos acontecimentos. Às vezes, muito mais do que apenas dar nossa opinião, queremos convencer as outras pessoas sobre o nosso ponto de vista. Só que convencer alguém pode não ser tarefa fácil, é preciso saber construir estratégias de convencimento.

Quando a situação permite que nossa opinião seja dada apenas na modalidade oral, sobretudo, quando a situação é mais informal, sentimo-nos mais seguros, porque a construção de nosso discurso pode ser feita de forma mais natural. Mas, existem muitas situações que requerem certa formalidade e exigem a produção de textos escritos, os quais precisam de mais elaboração, de mais planejamento por parte do autor, precisam estar adequados ao lugar onde serão publicados. 
Alguns exemplos de textos escritos classificados como texto de opinião, uma vez que apresentam a opinião do autor (o que também é chamado de ponto de vista) e estratégias de convencimento (chamadas de argumentos) estão presentes em jornais e revista. Por exemplo: o Editorial, a Carta do leitor, a charge, o artigo de opinião. Os textos de opinião também estão presentes em exames admissionais, como é o caso do vestibular e do Enem. Mas, você sabe qual é a diferença que existe entre eles? É possível enumerar uma série de diferenças, porém, vamos, nesse momento, identificar apenas algumas.

\begin{tabular}{|l|l|l|l|}
\hline Gênero & $\begin{array}{l}\text { Qual o papel social da- } \\
\text { quele que produz esse } \\
\text { gênero? }\end{array}$ & $\begin{array}{l}\text { Qual é a função desse gêne- } \\
\text { ro? Isto é, para que ele existe } \\
\text { na sociedade? }\end{array}$ & $\begin{array}{l}\text { Quem é o leitor/desti- } \\
\text { natário deste gênero? }\end{array}$ \\
\hline Editorial & & & \\
\hline Carta do leitor & & & \\
\hline Charge & & & \\
\hline $\begin{array}{l}\text { Artigo de } \\
\text { opinião de jornal }\end{array}$ & & & \\
\hline
\end{tabular}

Após discutir os resultados dessa atividade com os colegas, observe um exemplar da prova do Enem. Na redação o autor deve defender uma tese - uma opinião - a respeito do tema proposto pelo exame, se apoiando em argumentos e ainda construir uma proposta de intervenção social para o problema em abordagem. Ao saber disso, responda:

1. Em todos os textos de opinião, o tema abordado é considerado um tema polêmico. $\mathrm{O}$ que é um tema polêmico?

2. Qual é a função social da redação no Enem? Para que ele serve?

3. A redação do Enem é elaborada por um instituto ligado ao Ministério da Educação brasileiro, que responde ao presidente da república em exercício, sendo assim, quais os temas possíveis de serem proposto pelo exame?
4. É possível tratar o tema, por exemplo, "problemas com a mobilidade urbana" na redação do Enem da mesma forma em que em um artigo de opinião a ser publicado no jornal de nossa região (interior do estado; um pequeno centro urbano)? Explique sua resposta.

As questões visam trabalhar os aspectos do contexto extraverbal (VOLOCHINOV, 2013) que formam o Enem, aspectos diferentes daqueles que constituem outros contextos, e do fato de que conforme o campo da atividade humana da qual está inserido o indivíduo, o conteúdo temático do enunciado é tratado de forma diferente diante das particularidades do campo, porque um texto de opinião apesar de estar sempre permeado pela idiossincrasia, também é formado, igualmente, pelos preceitos sociais coletivos 
instituídos em cada uma dos diferentes campos (BAKHTIN/VOLOCHINOV, 2006). Assim, os temas, por exemplo, da falta de investimento do governo na infraestrutura dos hospitais braseiros, a falta de investimento em saneamento básico, que são assuntos controversos, que geram opinião diversas, podem ser temas de textos do campo jornalístico, de conversas cotidianas familiares, mas não de redação do Enem.

Oficina 3: O conteúdo temático, a construção composicional e o estilo do gênero.

De acordo com Angelo e Menegassi (2016, p. 49), "as atividades sociocomunicativas desempenhadas pelos parceiros da comunicação, as ocorrências da língua, só se tornam possíveis por meio de uma forma textual". Nesse sentido, a oficina três aborda as formas da língua (BAKHTIN/VOLOCHINOV, 2006), isto é, os elementos que formam a construção composicional e do estilo do gênero redação do Enem. Conforme Bakhtin (2003, p. 296), "o enunciado, seu estilo e sua composição são determinados pelo elemento semântico-objetal e por seu elemento expressivo, isto é, pela relação valorativa do falante com o elemento semântico-objetal do enunciado". Assim, o conteúdo temático é não somente o tema tratado em um texto, mas, também, a valoração que esse tema recebe do autor, da consideração do autor sobre em qual campo está acontecendo a interação e sobre quem são seus interlocutores.
ATIVIDADE: Faça a leitura de um exemplar de redação do Enem disponibilizado pelas mídias por ter alcançado a nota máxima no exame, 1.000 pontos $^{6}$. Agora veja o que a Cartilha do participante explica sobre a prova de redação:

A prova de redação exigirá de você a produção de um texto em prosa, do tipo dissertativo-argumentativo, sobre um tema de ordem social, científica, cultural ou política. Os aspectos a serem avaliados relacionam-se às competências que devem ter sido desenvolvidas durante os anos de escolaridade. Nessa redação, você deverá defender uma tese - uma opinião a respeito do tema proposto -, apoiada em argumentos consistentes, estruturados com coerência e coesão, formando uma unidade textual. Seu texto deverá ser redigido de acordo com a modalidade escrita formal da língua portuguesa. Você deverá, também, elaborar uma proposta de intervenção social para o problema apresentado no desenvolvimento do texto que respeite os direitos humanos (BRASIL, 2017, p. 7).

\section{Responda:}

1. Qual é o tema em abordagem no exemplar em estudo?

2. Qual a valoração que o autor da redação tem sobre o tema, isto é, qual é o ponto de vista do autor sobre o tema?

3. A valoração que você dá ao tema é a mesma que o autor do exemplar em estudo? Explique sua resposta.

4. Em qual parte do texto o ponto de vista (também chamada de tese) do autor é apresentada?

5. Diante do fato da redação do Enem ser um texto de opinião, como vimos em atividades anteriores, o ponto de 
vista poderia ser apresentado em outro momento do texto? Justifique sua resposta.

6. Leia uma entrevista publicada no sítio "Rede Mobilizadores sobre intolerância religiosa"7. Observe qual é a opinião da pessoa entrevistada sobre o mesmo tema; e identifique: a opinião da autora é apresentada na estrutura do texto em quais lugares?

7. Por que a exposição das opiniões dos autores é estruturada na entrevista de um jeito e na redação do Enem de outro?

Destacamos, novamente, que as atividades são norteadas pelo princípio de que o enunciado, como material observável, concreto, está marcado em sua composição estrutural pelo diálogo entre os participantes da interação. A Cartilha do Enem prescreve que o autor deve apresentar seu ponto de vista de forma explícita: tese - argumentos - proposta de intervenção. Em uma entrevista, sendo retextualizada para a modalidade escrita da língua, a opinião do autor vai sendo exposta diante das perguntas construídas pelo entrevistador e diante dos diferentes objetivos que possa ter o entrevistado, de sua consciência sobre quem são seus leitores; de quem é o veículo de circulação de seu texto etc.

É preciso também levar o aluno a compreender que cada pessoa tem seus valores pessoais, suas opiniões próprias, mas esses valores são construídos e devem se relacionar com os que regem as convenções sociais de um tempo e de uma época determinada, com os discursos precedentes e com os esperados como posteriores, como explica Menegassi e Cavalcanti (2013). Nesse sentido, está a instrução do Enem de que os direitos humanos não podem ser agredidos pelo participante, sob pena até da redação receber nota zero.

8. De acordo com a Cartilha do participante, existes diferentes tipos de estratégias argumentativas que podem ser utilizadas para desenvolver argumentos, de modo a convencer o leitor: exemplos; dados estatísticos; pesquisas; fatos comprováveis; citações ou depoimentos de pessoas especializadas no assunto; pequenas narrativas ilustrativas; alusões históricas; e comparações entre fatos, situações, épocas ou lugares distintos. Volte ao texto e busque identificar se o autor utilizou, e em que momento o fez, alguns desses tipos de estratégias.

9. Quantos parágrafos o autor utilizou para apresentação dos argumentos? Qual o motivo dessa organização?

10. Volta a sua resposta para a questão de número 3 desta atividade. A partir do ponto de vista que você apresentou para o tema, construa um argumento - que pode ser um exemplo, um dado estatístico, o resultado de uma pesquisa (reveja os tipos de estratégias argumentativas expostas na questão de número 6). 
11. Atenção ao alerta dado pela Cartilha do Participante (BRASIL, 2017, p. 18):

\section{ATENÇÃO!}

Será atribuída nota zero à redação que não obedecer à estrutura dissertativo-argumentativa, mesmo que atenda às exigências dos outros critérios de avaliação. Você não deve, portanto, elaborar um poema ou reduzir o seu texto à narração de uma história ou a um depoimento de experiência pessoal. No processo argumentativo, é possível apresentar trechos narrando acontecimentos que justificam a tese, mas o texto não pode se reduzir a uma narração, por esta não apresentar os princípios de estruturação solicitados.

Pesquise e traga para a próxima aula um texto construído pela predominância da narração. Vamos compreender as diferenças entre um texto que narra acontecimentos e um que argumenta sobre acontecimentos.

Os tipos de argumentos, bem como o fato do exame valorizar a aplicação no texto de conceitos de outras áreas do conhecimento no desenvolvimento do tema dizem respeito à construção do que o Círculo de Bakhtin denomina de arena de vozes, é trazer a consonância ou a dissonância do autor da redação outros discursos anteriores que o constituíram, que auxiliaram na formação de seus valores.

12. Uma boa proposta de intervenção, conforme a Cartilha do participante, contem "não apenas a exposição da ação interventiva sugerida, mas também o ator social competente para executá-la de acordo com o âmbito da ação escolhida: individual, familiar, comunitário, social, político, governamental e mundial" (BRASIL, 2017, p. 24). Volte ao texto e responda:

a) $\mathrm{O}$ autor da redação deixou claro quem é responsável por executar a ação interventiva? Esse responsável é uma ou mais pessoas?

b) Essa proposta de responsabilização é coerente, isto é, seria possível que essa pessoa ou essas pessoas tivessem concretamente como realizar a ação interventiva?

c) $\mathrm{O}$ autor aponta um possível meio para que ação interventiva possa ser realizada? Esse apontamento é coerente? Justifique sua resposta.

13. De quantos parágrafos o autor se ocupou para a apresentação da proposta de intervenção? Justifique a estratégia utilizada nessa organização.

Para o trabalho com os elementos que formam o estilo do gênero: as palavras e as formas gramaticais escolhidas para organizar o conteúdo temático (BAKHTIN, 2003), as atividades visam levar os graduandos a compreender que elas estão determinadas pela situação comunicativa e sobre os papéis que ocupam os interlocutores da interação. $\mathrm{O}$ autor do texto é um candidato a uma vaga no 
ensino superior e seu destinatário é uma banca formada por dois professores de Língua Portuguesa, portanto, a organização dos elementos linguístico-discursivos deve se adequar a uma modalidade mais formal da língua. Dessa forma, o estilo é a adequação textual à enunciação, legitimada pelos critérios expostos na Cartilha do participante. De acordo com Bakhtin (2003, p. 266),

[...] no fundo, os estilos de linguagem ou funcionais não são outra coisa senão estilos de gênero de determinadas esferas da atividade humana e da comunicação. Em cada campo existem e são empregados gêneros que correspondem às condições específicas de dado campo; é a esses gêneros que correspondem determinados estilos.

Em decorrência, o trabalho com as pessoas do discurso na proposta interventiva tem o objetivo de deixar claro que mesmo que não marcado linguisticamente na Cartilha, o que é pelo exame valorizado está no extraverbal, segundo Menegassi e Cavalcanti (2013, p. 435),

[...] o extraverbal é caracterizado pelo que não foi dito explicitamente, portanto, não marcado em linguagem verbo-visual, em que o contexto pode ser compreendido pelos envolvidos na interação por meio de circunstâncias não linguísticas conhecidas pelos interlocutores e que complementam o sentido que se quer dar aos enunciados. Muitas vezes, pode ser visto apenas como uma imagem que complementa os enunciados, o não verbal, mas vai além ao manter a característica social que faz parte das interações verbais.

Cabe justamente ao interlocutor identificar essas características no meio social, para que a compreensão do enunciado se qualifique, permitindo que a interação se instale e a enunciação se efetive, gerando o ato comunicativo.

\section{(Continuação das atividades da oficina 3)}

Os recursos gramaticais são essencialmente relevantes na construção de sua redação, são eles que articulam as ideias, os conceitos expostos, os argumentos, colaborando de forma direta para a construção dos sentidos do texto e para adequação do texto a que propõe o Enem. Lembre-se também de que a Competência 1 prescreve que o autor da redação deve obrigatoriamente demonstrar em seu texto domínio da modalidade escrita formal da Língua Portuguesa - entre os motivos que justificam esse fato está a questão do leitor e corretor de seu texto ser uma banca formada por dois professores de língua portuguesa. Assim, vejamos:

Se a redação do Enem é um texto no qual o autor apresenta sua opinião, então, esse autor pode utilizar-se da primeira pessoa do discurso, visto que a opinião apresentada sobre o tema é pessoal. Porém, como também já vimos, em algumas situações é preciso que o modo como nossa opinião é apresentada esteja adequada ao lugar, ao objetivo, a quem se dirige nosso texto.

1. Vamos fazer a leitura de mais dois exemplares de redações nota $1.000 \mathrm{e}$ identificar qual a pessoa do discurso que organiza o discurso nesses textos. Apesar da Cartilha do participante (BRASIL, 2017) não expor nenhuma orientação específica sobre qual pessoa do discurso empregar, ao conhecermos as redações que receberam a nota máxima 
(1000 pontos) em todas as edições do Enem, é visível que muitos dos textos nota 1000 são produzidos empregando o modo impessoal ou fazendo uso da terceira pessoa do singular.

A impessoalidade corresponde ao emprego, pelo autor de um texto, da terceira pessoa do singular, de verbos na voz ativa, com o uso da partícula se. $\mathrm{O}$ emprego desses recursos confere um tom universal no tratamento ao tema proposto. Ao empregar essa pessoa do discurso, um texto ficaria assim, por exemplo:

Nesse contexto, salienta-se, segundo Sócrates, os erros são consequência da ignorância humana. Logo, analisa-se que o desconhecimento acerca de crenças diferentes influi decisivamente em comportamentos inadequados contra pessoas que seguem linhas de pensamento opostas. Em vista disso, ressalta-se que, em algumas religiões, o contato com perspectivas de outras crenças não é permitido.

Contudo, é importante perceber que a maioria dos textos que receberam nota 1000 utilizam-se de construção como essa:

Nesse contexto, segundo Sócrates, os erros são consequência da ignorância humana. Logo, o desconhecimento acerca de crenças diferentes influi decisivamente em comportamentos inadequados contra pessoas que seguem linhas de pensamento opostas. Em vista disso, em algumas religiões, o contato com perspectivas de outras crenças não é permitido. a) Qual é a pessoa do discurso que organiza o trecho?

b) Qual a diferença de sentido do segundo trecho em relação ao primeiro?

2. Conforme a Cartilha do participante, a organização textual exige que as frases e os parágrafos estabeleçam entre si uma relação que garanta a sequência coerente do texto e a interdependência entre as ideias. Esse encadeamento pode ser expresso por conjunções.

Conjunções: Na língua portuguesa, existem palavras ou expressões responsáveis por dar força argumentativa aos enunciados. Considerando que a redação do Enem é um texto predominantemente argumentativo, essas palavras, comumente chamadas de conjunções são importantíssimas na construção desse gênero textual. O importante não é saber a classificação de cada uma das conjunções, é saber utilizá-las no texto para construir o sentido que você quer dar a ele.

Então responda: "A Constituição Federal de 1988 - norma de maior hierarquia no sistema jurídico brasileiro - assegura a todos a liberdade de crença. Entretanto, os frequentes casos de intolerância religiosa mostram que os indivíduos ainda não experimentaram esse direito na prática”. Qual é o sentido que a conjunção ENTRETANTO confere ao trecho?

O trecho a seguir é o último parágrafo de uma redação do Enem: "Urge, portanto, que indivíduos e instituições públicas cooperem para mitigar a intolerância 
religiosa. Cabe aos cidadãos repudiar a inferiorização das crenças e dos costumes presentes no território brasileiro...”. Qual é o sentido que ganha a expressão PORTANTO no último parágrafo de um texto?

Destacamos aqui dessas atividades que de acordo com Bakhtin (2003, p. 23), "as formas gramaticais não podem ser estudadas sem que se leve em conta seu significado estilístico. Quando isolada dos aspectos semânticos e estilísticos da língua, a gramática inevitavelmente degenera em escolasticismo".

As oficinas apresentadas são, dentro do esquema da sequência didática, o que Dolz, Noverraz e Schneuwly (2004) denominam de módulos. Após o levantamento do que é preciso ser tomado como objeto de ensino e aprendizagem, realizado nas primeiras produções, os módulos/oficinas de trabalho são planejados e implementados. Em seguida, é o momento da produção final.

\section{Considerações sobre a produção final}

Reproduzimos aqui a redação final de autoria do mesmo acadêmico do Texto 2 :

\section{Texto 3:}

De comportamentos estúpidos embora até mesmo inofensivos - até suicídios e assassinatos cometidos por adolescentes foram, muitas vezes, creditados na conta da influência causada pela televisão e, mais recentemente, pela internet. Entretanto, pessoas em fase de formação estão, naturalmente, muito abertas a influências de todos as áreas e por isso as mídias não podem ser culpadas dos comportamentos de adolescentes, são os responsáveis por pessoas nessa fase que devem acompanhar o que está acontecendo, o que os adolescentes vêm na TV e internet, com quem eles se relacionam, no virtual ou real, o que eles estão sentindo diante do mundo.

Não é novidade que a televisão e a web utilizam de discursos de modo a alcançarem diferentes objetivos, mas, dentre eles, os que consideramos o principal é o econômico/comercial, influenciar as pessoas a comprarem produtos e serviços, pois são os comerciais que patrocinam os programas, eles é que dão lucro as mídias. Assim, a maior influência exercida pela mídia sobre as pessoas é o consumismo. Porém, esse aspecto não é o que ganha maior repercussão nas discussões sobre os novos hábitos, sobretudo, hábitos negativos de nossa sociedade contemporânea. O comprar, porque vimos na TV e na internet, porque meu amigo tem, porque todo mundo está usando, não é a preocupação primeira. Mesmo que isso possa causar, junto a outros motivos, uma depressão e portanto até a morte. O que a sociedade se preocupa é com o que pode levar a morte de forma direta, por isso "games" já foram apontados como a causa do desvirtuamento de jovens (jogos onde o personagem atropela e mata, por exemplo). 
Recentemente foi descoberto um jogo no web chamado de "Baleia azul" que levo o participante a percorrer desafios de autotortura. Caso não cumpram as etapas, os participantes eram ameaçados pelos demais, o que causou alguns suicídios de adolescentes. Mas o que muitas vezes as pessoas não sabem é que alguns dos adolescentes que decidiram participar do jogo, sofriam de depressão, e que em alguns casos esse fato era desconhecido pelos pais. A adolescência é um período complexo de transição, muitas pessoas dessa faixa etária sentem-se perdidas e insatisfeitas com tudo a sua volta e consigo mesmo. Esta é a fase em que os pais mais devem atentar para à situação dos seus filhos, pois estão frágeis, o que os tornam manipuláveis. É possível perceber então, que não é o jogo ou só um jogo que leva os jovens ao extremo.

A sociedade sempre busca um culpado para comportamentos que saem do padrão, e esse culpado por muito tempo tem sido a televisão e mais recentemente a internet. Mas o padrão deveria ser uma sociedade consciente da necessidade de que os adultos, os responsáveis acompanhassem de parte o desenvolvimento das crianças e dos adolescentes. Seja para combater o consumismo, as injustiças, a manipulação do mais forte físico e mentalmente sobre aqueles que estão em processo de formação de identidade. A mídia, como apontamos, vai ter sempre o papel de influenciadora, o que é preciso é cuidar para que a influência seja positiva, o que é papel dos pais, dos responsáveis por aqueles que ainda não tem discernimento para compreender as coisas do mundo.

São aqueles que têm experiência que devem cuidar das crianças e dos jovens. Eles é quem devem mantê-los afastados de programas e sites que não são próprios para eles. Cabe aos adultos o papel de lutar, social e politicamente, para que as mídias assumam papéis mais sociais, educativos, construtivos para uma sociedade mais igualitária e altruísta. Para que assim os adolescentes exerçam também quando adultos o mesmo papel. $\mathrm{O}$ cidadão comum também tem espaço na mídia, pequenos espaços que promovem que opiniões, reclamações, sugestões possam ser publicadas.

Nessa nova versão, a relação de sentidos com os discursos instituídos no sistema de normas coletivas (BAKHTIN/ VOLOCHINOV, 2006), na Cartilha do participante, com os enunciados que formaram os exercícios interventivos e com a primeira versão produzida pelo graduando se estabelece nos seguintes aspectos: no papel social que o autor assume diante do contexto extraverbal (VOLOCHINOV, 2013), se apresentando como alguém que tem conhecimentos a respeito das questões que conduzem a vida em sociedade e, por isso, pode dar uma opinião a respeito de um assunto que é problemático, oferendo proposta de solução para o problema, diante das regras e normas exigidas pela situação da 
qual ele participa e de quem são seus interlocutores. $\mathrm{O}$ graduando se coloca como um sujeito que tem valores individuais, mas que se reconhece como integrante de um contexto e do que se espera dele na situação social imediata (BAKHTIN/ VOLOCHINOV, 2006). Por exemplo, por meio da modalização, a afirmação é a de que: "De comportamentos estúpidos - embora até mesmo inofensivos - até suicídios e assassinatos cometidos por adolescentes foram, muitas vezes, creditados na conta da influência causada pela televisão e, mais recentemente, pela internet”. Organização textual que está relacionada à exigência de que o texto tenha coerência textual (competência 4), um dos fatores que formam a coerência é a não contradição às questões que existem no mundo, que é o que faz o graduando, afirma que muitas vezes se culpa a TV e a internet pelos comportamentos, mas isso não é via de regra, que é o que está posto explicitamente no enunciado que forma o tema da redação: "Imagens, discursos e representações sociais presentes na mídia televisiva e na web podem ser incorporados...". Nesse sentido, o autor recupera um discurso comum, estabilizado socialmente, que acontece "muitas vezes", que é o de culpar as mídias. Mas ele marca sua própria valoração sobre o tema, por isso a importância do emprego da conjunção "entretanto" no trecho:

De comportamentos [...], muitas vezes, creditados na conta da influência causada pela televisão e, mais recen- temente, pela internet. Entretanto, pessoas em fase de formação estão, naturalmente, muito abertas a influências de todos as áreas e por isso as mídias não podem ser culpadas dos comportamentos de adolescentes, são os responsáveis por pessoas nessa fase que devem acompanhar o que está acontecendo, o que os adolescentes vêm na TV e internet, com quem eles se relacionam, no virtual ou real, o que eles estão sentindo diante do mundo.

O posicionamento idiossincrático (BAKHTIN, VOLOCHINOV, 2006), isto é, a tese defendida é a de que os responsáveis pelos adolescentes serem influenciados pelas mídias é dos responsáveis por essas pessoas que em fase de formação são naturalmente abertas a influências de todos os tipos. Na primeira versão, o graduando apenas tangencia o fato de os pais serem os culpados pela influência da mídia sobre os jovens, o que é exposto, como um ponto de vista nos dois últimos parágrafos do texto 2. Esse aspecto foi tomado como objeto de ensino na oficina 3 , as atividades se voltaram a trabalhar o plano estrutural considerando os motivos de um texto se estruturar como texto dissertativo-argumentativo. Na nova versão, o autor expõe a tese no primeiro parágrafo, como já demonstrado, e depois passa a construir argumentos, a fim de convencer seu interlocutor a respeito de seu posicionamento.

Primeiro parágrafo, a tese - “...pessoas em fase de formação estão, naturalmente, muito abertas a influências de 
todos as áreas ...”; “... são os responsáveis por pessoas nessa fase que devem acompanhar o que está acontecendo, o que os adolescentes vêm na TV e internet, com quem eles se relacionam, no virtual ou real, o que eles estão sentindo diante do mundo". Segundo parágrafo: o autor explica a natureza influenciadora da mídia. Terceiro parágrafo: explicação sobre a influência que naturalmente que a fase da adolescência recebe e a responsabilização dos pais como acompanhantes dos acontecimentos. Quarto parágrafo: volta a abordagem sobre a busca da sociedade por culpados e dá nova explicação sobre a responsabilidade dos adultos. Quinto parágrafo: a organização do fechamento da proposta de intervenção que envolveu tudo que foi exposto no texto de uma forma geral. Ação que dialoga com os critérios do Enem (avaliação da Competência 5).

Ainda sobre a proposta de intervenção, em relação de sentido com o prescrito na Cartilha: "deve contar o meio de execução da ação e seu possível efeito, bem como o detalhamento da ação ou do meio para realizá-la" (BRASIL, 2017, p. 24) - no Texto 3, o graduando constrói uma proposta marcada linguisticamente por essas referências, embora em uma proposição e articulação mediana:

São aqueles que têm experiência que devem cuidar das crianças e dos jovens. Eles é quem devem mantê-los afastados de programas e sites que não são próprios para eles. Cabe aos adultos o papel de lutar, social e politicamente, para que as mídias assumam papéis mais sociais, educativos, construtivos para uma sociedade mais igualitária e altruísta. Para que assim os adolescentes exerçam também quando adultos o mesmo papel. $\mathrm{O}$ cidadão comum também tem espaço na mídia, pequenos espaços que promovem que opiniões, reclamações, sugestões possam ser publicadas

$\mathrm{E}$, mesmo que o texto ainda apresente desvios na organização da textualidade, o autor revela ter selecionado recursos linguísticos e estilísticos de acordo com o tema; expõe sua valoração individual e relaciona-se com quem são seus destinatários (BAKHTIN, 2016). Em decorrência: demonstra domínio mediano da modalidade formal da língua, mas com alguns desvios gramaticais (competência 1). Portanto, busca adequar o texto ao seu interlocutor (BAKHTIN/VOLOCHINOV, 2006); desenvolve o tema por meio de argumentação (competência 2). Embora os argumentos partam de questões simples, sem articulação com aspectos históricos, em relação com outras áreas do conhecimento (como sugere a Cartilha do participante), o autor estrutura o texto dentro da proposta temática, com proposição, argumentação e apresentação de intervenção, que é uma ação condicionada aos fatores do contexto extraverbal (VOLOCHINOV, 2013), conforme mencionado.

A competência 3 está contemplada na produção final, o autor apresenta informações e opiniões relacionados ao tema; assim como a competência 4: 
articula as partes do texto com algumas inadequações, mas apresenta repertório de recursos coesivos; 5: elabora proposta de intervenção relacionada ao tema e articulada à discussão desenvolvida no texto.

Em decorrência, o texto não é apenas um produto e processo da verificação docente do ensino e aprendizagem de conteúdo, a redação em questão materializa um gênero que agora reflete o campo e a prática social do Enem. Diferente do que aconteceu na primeira versão (Texto 2), nessa versão (Texto 3), o tema é tratado diante de um posicionamento social do autor de maneira articulada; o autor demonstra saber qual é o seu papel social na produção do gênero e o papel de seu destinatário dentro da interação em questão.

\section{Considerações finais}

Durante o processo de formação de docentes graduandos, participantes de um projeto Pibid, a fim de prepará-los para atuarem em sala de aula da educação básica como mediadores do ensino e da aprendizagem da produção textual da redação do Enem, elaboramos estudos dirigidos e solicitamos, em formato de simulado, que produzissem um exemplar do gênero. Ao analisarmos os textos produzidos pelos graduandos, encontramos muitos problemas, não só relacionados à adequação da organização dos elementos estilístico e composicionais exigidos pelo Enem na produção da redação, mas, sobretudo, questões que envolvem a natureza dos enunciados que não refletiam a situação comunicativa na qual a interação estava inserida. A primeira produção revelou que eles não conheciam o papel social do qual deveriam se ocupar para a produção do gênero em trabalho, tão pouco quem eram os interlocutores; que as escolhas estilísticas e organização estrutural se estabeleciam muito mais pela situação específica de comunicação do que serem apenas regras impostas pelos organizadores do Enem. Os acadêmicos não sabiam, até aquele momento, produzir um gênero textual adequado à situação comunicativa que foi tomada como eixo organizador das atividades de ensino do Pibid, bem como adequado ao próprio campo onde estavam naquele momento inseridos, o campo acadêmico.

Diante dessas questões, elaboramos e implementamos uma proposta de intervenção pedagógica, o que culminou na produção de uma nova versão do texto, a qual demonstrou que o texto deixou de ser apenas um gênero acadêmico constituído como processo e produto da verificação docente do ensino e aprendizado de conteúdos para se tornar um gênero textual que materializa uma prática social instituída no Enem.

Diante do exposto, esperamos que este trabalho possa contribuir com pesquisadores e professores interessados no aprimoramento da prática discursiva de produção de textos por alunos do ensino superior, a fim de que o prescrito pelos documentos orientadores seja transposto 
para a sala de aula e que os graduandos possam se qualificar para o trabalho e para o exercício da cidadania.

\section{The development of genre of the argumentative discourse in higher education: a theoretical- methodological proposal}

\section{Abstract}

This study aims to present a theoretical-methodological proposal for the work with the textual production of argumentative discourse in higher education. Sustained by the dialogical conception of language, originating from the precepts of the Bakhtin Circle, and by the principles of the didactic strand of Socio-discursive Interactionism, the proposal is an extension of what was accomplished in the training of students of the course of Letters for the execution of the PIBID project. After analysis of diagnostic texts produced by the undergraduates, a didactic sequence was elaborated and implemented. The final production of the academics showed that the proposal contributed to the fact that the text was no longer just an academic genre constituted as a process and product of the teaching verification of teaching and learning of contents to become a materialization of a social practice instituted in a situation of specific interaction.

Keywords: Discursive genres; Dialogical relationship; Text production; Higher education.

\section{Notas}

1 Os termos acadêmicos, graduandos e professores em formação inicial são tomados como sinônimos, em função do público-alvo investigado.

2 Disponível em: http://download.inep.gov.br/ educacao_basica/enem/edital/2017/edital enem_2017.pdf. Acesso em: 18 abr. 2017.

3 Disponível em: http://download.inep.gov.br/ educacao_basica/enem/guia_participante/2017/ manual_de_redacao _ do_enem_2017.pdf. Acesso em: 18 abr. $201 \overline{7}$.

4 O texto 1 é um representante médio dos 10 textos, isto é, não é o mais problemático ou menos, entre os 10, é apenas um representante de um conjunto que expõe regularidades problemáticas.

5 A Matriz está disponível na página do Instituto Nacional de Estudos e Pesquisas Educacionais: www.inep.gov.br/ENEM.

6 Redação produzida sobre o tema: Caminhos para combater a intolerância religiosa no Brasil. Disponível em: http://g1.globo.com/ educacao/noticia/leia-redacoes-nota-mil-do-enem-2016.ghtml.

7 Disponível em: http://www.mobilizadores.org. br/entrevistas/nao-podemos-mais-falar-de-intolerancia-religiosa-mas-sim-de-violencia/. Acesso em: 01 jul. 2016.

\section{Referências}

ANGELO, C.N.P.; MENEGASSI, R.J. O trabalho docente com a coesão em sala de apoio à aprendizagem. In: OHUSCHI, M.C.G.; MENEGASSI, R.J. (Org.). Dialogismo, interação em práticas de linguagem no ensino de línguas. Castanhal, PA: UFPA/Faculdade de Letras, 2016, p. 49-64.

BAKHTIN, M. Estética da criação verbal. Trad. Paulo Bezerra. 4. ed. São Paulo/SP: Martins Fontes, 2003.

Os gêneros do discurso. Organização e tradução de Paulo Bezerra. São Paulo/SP: Editora 34, 2016.

BAKHTIN, M./VOLOCHINOV, V. Marxismo e filosofia da linguagem. 12. ed. São Paulo/ SP: Hucitec, 2006. 
BRASIL. Lei de Diretrizes e Bases da Educação Nacional - LDB Lei no 9394/96.

. Secretaria de Educação Fundamental. Parâmetros curriculares nacionais: Língua Portuguesa. Brasília. Secretaria de Educação Fundamental, 1998.

Diretriz Curricular Nacional do Curso de Letras. Disponível em: http://portal. mec.gov.br/observatorio-da-educacao/323-secretarias-112877938/orgaos-vincula dos-82187207/12991-diretrizes-curriculares-cursos-de-graduacao. Acesso em: 21 jul. 2018.

Ministério da Educação. Base Nacional Comum Curricular: educação é a base. Brasília, 2017.

BRONCKART, J.P. Atividade de linguagem, textos e discurso: por um interacionismo sociodiscursivo. Tradução Anna Rachel Machado e Péricles Cunha. 2. ed. São Paulo: Educ, 2009.

DOLZ, J.; SCHNEUWLY, B. Gêneros e progressão em expressão oral e escrita: elementos para reflexões sobre uma experiência suíça (francófona). In: SCHNEUWLY, B.; DOLZ, J. e colaboradores. Gêneros orais e escritos na escola. Tradução e organização Roxane Rojo e Glaís Sales Cordeiro. Campinas/SP: Mercado das Letras, 2004, p. 41-70.

; NOVERRAZ, M.; SCHNEUWLY, B. Sequências didáticas para o oral e a escrita: apresentação de um procedimento. In: SCHNEUWLY, B.; DOLZ, J. e colaboradores. Gêneros orais e escritos na escola. Tradução e organização Roxane Rojo e Glaís Sales Cordeiro. Campinas/SP: Mercado das Letras, 2004, p. 95-128.

FIORIN, J. L. Introdução ao pensamento de Bakhtin. São Paulo: Ática, 2008.

MARINHO, M. A escrita nas práticas de letramento acadêmico. Revista Brasileira de Linguística Aplicada. Belo Horizonte, v. 10, n. 2, abr./jun. 2010, p. 363-386.
MENEGASSI, R. J.; CAVALCANTI, R.S.M. Conceitos axiológicos bakhtinianos em propaganda impressa. Alfa, São Paulo, n. 57, v. 2, p. 433-449, 2013.

ROJO, R.; BARBOSA, J.F. Hipermodernidade, multiletramentos e gêneros discursivos. São Paulo: Parábola, 2015.

VITÓRIA, M. I. C.; CHRISTOFOLI, M. C. P. A escrita no ensino superior. Educação. Santa Maria, v. 38, n. 1, p. 41-54, jan./abr., 2013.

VOLOCHINOV, V.N. A construção da enunciação e outros ensaios. São Carlos: Pedro \& João Editores, 2013. 